\title{
Statewide Implementation of Virtual Perinatal Home Visiting During COVID-19
}

\author{
Jennifer Marshall ${ }^{1}\left[\right.$ ( Laura Kihlström $^{1} \cdot$ Acadia Buro $^{1} \cdot$ Vidya Chandran $^{1} \cdot$ Concha Prieto $^{1} \cdot$ Rafaella Stein-Elger $^{1}$. \\ Keryden Koeut-Futch ${ }^{1} \cdot$ Allison Parish ${ }^{2} \cdot$ Katie Hood ${ }^{2}$
}

Published online: 20 July 2020

○) Springer Science+Business Media, LLC, part of Springer Nature 2020

\begin{abstract}
Purpose This evaluation describes efforts taken by MIECHV administrators and staff during the pandemic using data collected from 60 MIECHV staff surveys and nine statewide weekly focus groups.

Description The Florida Maternal, Infant and Early Childhood Home Visiting (MIECHV) Initiative funds perinatal home visiting for pregnant women and families with infants throughout the state. Florida MIECHV has shown resilience to disasters and times of crises in the past, while generating a culture of adaptation and continuous quality improvement among local implementing agencies. Florida MIECHV responded to the COVID-19 pandemic crisis within the first few days of the first reported case in Florida by providing guidance on virtual home visits and working remotely.

Assessment Findings highlight the role of administrative leadership and communication, staff willingness/morale, logistical considerations, and the needs of enrolled families who face hardships during the pandemic such as job loss, limited supplies, food insecurity, technology limitations, and stress. Home visitors support enrolled families by connecting them with resources, providing public health education and delivering evidence-based home visiting curricula virtually. They also recognized the emotional burden surrounding COVID-19 impacts and uncertainties along with achieving work-life balance by caring for their own children.

Conclusion This evaluation helped in understanding the impact of the pandemic on this maternal and child health program and fundamentals of transition to virtual home visiting services. Virtual home visiting appears to be feasible and provides an essential connection to supports for families who may not otherwise have the means or knowledge to access them.
\end{abstract}

Keywords COVID-19 pandemic $\cdot$ MIECHV $\cdot$ Virtual home visiting

\section{Significance}

This paper describes statewide implementation of virtual perinatal home visiting in high-risk communities and staff adaptations to working remotely. Home visiting staff report on their transition to working from home and on the needs of enrolled families. Administrative supports and processes

Jennifer Marshall

jm@usf.edu

1 University of South Florida College of Public Health, Chiles Center, 13201 Bruce B Downs Blvd, Tampa, FL 33612, USA

2 Florida Maternal, Infant and Early Childhood Home Visiting (MIECHV) Program, Florida Association of Healthy Start Coalitions, 2002 Old St. Augustine Road, Suite E-45, Tallahassee, FL 32301, USA are also described. As the COVID-19 pandemic continues, and social and economic consequences of the pandemic unfold, findings will be used to plan further efforts to support MIECHV staff and their clients.

\section{Introduction}

The Maternal, Infant, and Early Childhood Home Visiting (MIECHV) Initiative is funded by the Health Resources and Services Administration (HRSA) to all U.S. states and territories to provide perinatal home visiting support to pregnant women and families with infants in high-need communities. Florida MIECHV, operating since 2013, funds 16 local implementing agencies (LIAs) in 24 high-need communities and four contiguous counties across the state, and served 2883 families last year (Florida MIECHV 2019). 
Participating communities were identified through a 2010 statewide needs assessment, which calculated composite risk based on poverty, parent education, birth outcomes, and other demographic and socioeconomic factors. The grantee for this program is the Florida Association of Healthy Start Coalitions (FAHSC). FAHSC also contracts externally for professional development and an independent evaluation (miechv.health.usf.edu). Florida MIECHV, operating three evidence-based home visiting models-Nurse Family Partnership (NFP), Parents As Teachers (PAT), and Healthy Families America (HFA) - has demonstrated positive outcomes related to benchmark indicators in six areas: maternal and child health, childhood injuries and abuse and neglect, school readiness, domestic violence, family economic selfsufficiency, and coordination of services. Florida MIECHV programs have a history of adapting quickly and collaboratively during times of crisis, including: hurricanes Irma, Maria, and Michael; mass shootings; and immigration policy changes. The programs also collaborate when opportunities emerge, working together across sites for quality improvement initiatives and coordinating with state agencies.

The first cases of the 2019-novel Coronavirus (COVID19) were reported in December 2019 in Wuhan, China (Du Toit 2020), and the virus quickly spread worldwide. It is believed to have reached the U.S. in January 2020 (Centers for Disease Control and Prevention [CDC] 2020a; Holshue et al. 2020). The U.S. Department of Health and Human Services (DHHS) declared a State of Emergency on January 27, 2020 (U.S. Department of Health and Human Services [DHHS] 2020a), and the World Health Organization declared the outbreak a global pandemic on March 11, 2020 (CDC 2020b). The first COVID-19 case in Florida was reported in March 2020 and at the time of writing exceeds 100,000 (Florida Department of Health [FDOH] 2020). The COVID-19 pandemic is a particularly high threat in vulnerable populations (e.g., pregnant women, families with children, and low-income populations) and communities that lack resources to manage the infection (Dashraath et al. 2020). These groups have unique needs for care during the COVID-19 pandemic (e.g., Dunn et al. 2020; Qiao 2020), as many parents and caregivers face job loss and children are out of school and childcare (Cluver et al. 2020).

In response to the pandemic, states have taken steps to support modified home visiting operations for MIECHV (Zero to Three 2020). As of May 13, 2020, HRSA allocated $\$ 15$ million to support telehealth providers during the COVID-19 pandemic through the CARES Act to address the need for increased training and resources for telemedicine (DHHS 2020b). The Florida program had to rapidly adapt services to support enrolled families throughout the COVID19 crisis. Because the program is evidence-based, it adheres to specified guidance around home visiting curricula, participant enrollment, home visit completion/frequency, activities, and documentation. By the second week of March, Florida MIECHV leadership announced plans for transitioning to virtual operations, and by the third week provided written guidance that included: overarching principles; basic CDCinformed guidance on preventing COVID-19 transmission for staff, for their families, and for their clients; considerations for technology, security/confidentiality, and fidelity to home visiting model; guidance for educating families on COVID-19 resources (e.g., CDC and FDOH updates, mental health resources, contacting health care providers for concerns, and preparing supplies, quarantine and childcare); and suggestions for the LIA organizations to support their staff with contact information, regular communication, data entry contingency plans, restructuring group activities/events, and staff supervision.

In April, HRSA began sending updates regarding MIECHV grantee deadlines, responsibilities, and parameters for utilization of funds in compliance with Federal regulations. This evaluation of Florida's efforts was reviewed by the University of South Florida Institutional Review Board and determined exempt. Evaluation questions included: (1) How are home visitors/MIECHV staff doing in this situation (enforced physical distancing and virtual home visits), both personally and professionally?; (2) How do MIECHV home visitors/staff perceive that the families are doing?; (3) How are MIECHV home visitors/programs supporting enrolled families?; and (4) What resources and processes are needed to implement virtual perinatal home visiting in Florida MIECHV?

\section{Methods}

The evaluation was conducted using a statewide MIECHV staff survey and a series of weekly focus groups with program staff, administrators, and supervisors led by the state leadership team. The evaluation team surveyed staff via a secure Qualtrics survey link from April 1-April 13, 2020 with a series of questions on their role (supervisor/administrator, home visitor, or other), county served, extent to which visits were virtual, and open-ended questions corresponding to the evaluation questions above. Additionally, the state leadership team held nine weekly focus groups between March 24 and May 22; these calls are ongoing. Participation in the survey and focus groups/calls was anonymous; staff only provided their role and county served in the survey. The focus groups were facilitated by the statewide MIECHV Project Coordinator who prompted three open-ended questions about challenges, best practices/strategies, and logistics related to virtual home visiting. With participant permission, the calls were digitally recorded, transcribed, and transcriptions were reviewed for accuracy. 
Analysis on the obtained data from survey responses and focus group transcripts were conducted using deductive qualitative analysis approach. The open-ended survey responses and call transcripts were first reviewed to create an initial, deductive codebook focusing on three main domains pertinent to the research questions: (1) MIECHV Workforce Well-being (2) Family Needs (3) Virtual MIECHV Services (Table 1). Under each broad domain, several subcodes were identified. This initial deductive codebook was then used to code the qualitative survey data in Excel and transcripts in MaxQDA. Focus group data were coded by two research assistants (one PhD Anthropology candidate, and one Masters in Public Health student) who have 3-5 years of experience in qualitative data analysis. To ensure inter-rater reliability (dependability in the coding process), coding for the transcripts was done twice by two independent coders on two of the transcripts. The results from this coding process were then compared ( $77 \%$ agreement). Following initial coding, the codebook was refined and discrepancies were reconciled. Once all transcripts were coded, the results were summarized, based on content analysis and frequency in the coded transcript segments and surveys.

\section{Results}

In the first two weeks of April, 60 surveys from 17 supervisors/administrators, 38 home visitors, and 5 others were collected. According to the survey respondents, all but two programs had fully transitioned to virtual visits. By the

Table 1 MIECHV COVID-19 codebook for survey and focus group transcript analysis

\begin{tabular}{|c|c|c|}
\hline Domain/parent code & Subcode & Definition/example \\
\hline \multirow[t]{5}{*}{ MIECHV workforce wellbeing } & \# of staff who report that they are doing well & Mention coping well, adjusting, managing new demands \\
\hline & \# of staff who report that they are struggling & $\begin{array}{l}\text { Mention difficulty with transition, work-life balance, stress due } \\
\text { to the pandemic or work }\end{array}$ \\
\hline & Facilitators to staff adjustment & $\begin{array}{l}\text { Previous experience, support and cooperation with other } \\
\text { agencies, positive response from families to virtual services, } \\
\text { maintaining a sense of confidence and optimism }\end{array}$ \\
\hline & Barriers to staff adjustment & $\begin{array}{l}\text { Uncertainty and anxiety about the situation, work-life balance } \\
\text { (e.g. childcare), difficulties in reaching families by phone or } \\
\text { virtually, engaging/interacting with families (missing inper- } \\
\text { son contact, not being able to observe child-parent interac- } \\
\text { tion, concerns regarding domestic violence), helplessness } \\
\text { due to not being able to provide financial support to families, } \\
\text { confusion about budget amendments, worry about bench- } \\
\text { marks and expectations }\end{array}$ \\
\hline & Staff needs during COVID-19 & $\begin{array}{l}\text { Funds to purchase essential items for families), access to } \\
\text { MIECHV documents (separate, fillable forms; assisting } \\
\text { families in filing for unemployment; documents in multiple } \\
\text { languages), tips/activities for virtual home visits, flexibility } \\
\text { and understanding for staff and program requirements, equip- } \\
\text { ment (phone, data) for video conferencing, or "everything is } \\
\text { working smoothly, I have no additional needs" }\end{array}$ \\
\hline \multirow[t]{2}{*}{ Family needs } & Resources needed by families & $\begin{array}{l}\text { Financial assistance due to unemployment, lack of unem- } \\
\text { ployment benefits due to immigration status, mental health } \\
\text { services and support, medical services, childcare, internet or } \\
\text { data for phone, transportation, housing }\end{array}$ \\
\hline & Items needed by families & $\begin{array}{l}\text { Diapers, formula, wipes, or toiletries, food, disinfectant, clean- } \\
\text { ing supplies, medical supplies }\end{array}$ \\
\hline \multirow[t]{4}{*}{ Virtual MIECHV services } & Transition to virtual services & $\begin{array}{l}\% \text { of staff responding: most visits virtual vs. most visits virtual } \\
\text { with some in person vs. planning to transition to virtual }\end{array}$ \\
\hline & Logistics of virtual Services & $\begin{array}{l}\text { Virtual platforms, consent processes, phone apps, text mes- } \\
\text { sages or phone calls, enrolling new families virtually, privacy } \\
\text { concerns, client barriers (e.g. data, bandwidth) }\end{array}$ \\
\hline & Support provided to families & $\begin{array}{l}\text { Supplying essential items (e.g. dropping off to client), commu- } \\
\text { nication (listening, checking in, referrals, resources), public } \\
\text { health education, activities for children }\end{array}$ \\
\hline & Frequency of virtual services (survey analysis) & $\begin{array}{l}\text { \% reporting: providing services at the same frequency as before } \\
\text { COVID-19 vs. less frequent services compared to before } \\
\text { COVID-19 }\end{array}$ \\
\hline
\end{tabular}


following week, all programs had transitioned to virtual visits. Overall, staff reported that virtual home visits were going well; over $80 \%$ responded positively. The results below summarize what has been reported so far in the survey and nine weekly state-led focus groups.

\section{MIECHV Workforce Well-Being and Staff Adjustment to Virtual Home Visiting}

\section{Facilitators}

When asked how staff were adjusting to physical distancing and virtual home visits, most staff described that they felt supported and confident. Positive response from families was the most frequently mentioned $(n=31)$ facilitator to virtual home visiting. Some staff reported that families' positive response helped them to overcome their initial skepticism regarding the virtual visits.

I am currently doing virtual visits and my mommies [clients] are liking it. They are liking that we take them into consideration and not going and spreading germs from one house to the other. Some mommies have shared and voiced that they would not allow me to come visit them if I came in person because they are not the only family I see. -Home Visitor.

Maintaining a sense of confidence and optimism was also mentioned as an important facilitator during focus groups $(n=15)$ and on the survey (28 of 60). Staff described how the positive response from families fostered an optimistic approach.

It's just been amazing that everyone has just adapted to this. I'm just so proud of the whole team and all of MIECHV, honestly, because it sounds like everybody's doing the exact same thing. It just makes me proud to be a part of this. -Administrator/Supervisor.

Support from other home visitors and agencies was also mentioned as a facilitator in the weekly focus groups $(n=6)$. Regular virtual check-ins with staff and creative ways to boost staff morale contributed to feelings of support.

One way I've found to motivate my team is by having our celebration and kudos each time we meet. We also do some unique ways of I want to say affirming them. So, we have rounds of applause, roller coaster claps, and firecracker claps which we get from early childhood classrooms. They tend to like seeing that happen, so we find unique ways to motivate each other and make sure that we keep a positive spin on the current situation. So, I think that that does help. -Administrator/Supervisor.
Barriers Challenges with virtual interaction with families was the most commonly mentioned barrier to virtual home visiting $(n=12)$, including being unable to observe parentchild relationship due to lack of video, difficulty familiarizing clients to virtual software, and lack of efficient internet service.

We're just trying to transition our families into this new form of service division, being that we don't really have a lot of families who have the capacity to do, or the capability to do the virtual visit by Zoom, so we're having to rely on the telecommunication form of visit to serve this provision. So, just trying to navigate that and get our families comfortable with the whole process, but also figuring out how to meet the requirements that our models are wanting at the same time. -Administrator/Supervisor.

Other barriers to transitioning to virtual home visiting included concern regarding benchmark expectations and anxiety and uncertainty due to the pandemic.

We know performance measures are unfortunately going to take a dip in many cases... and so we're hoping that that will be loosened up a little bit and that there will be some understanding that everybody is doing the best they can. -Administrator/Supervisor. I mean, I'll be honest, our staff is feeling the stress of this pandemic that we're all experiencing. There's reporting not sleeping well, and having nightmares, and things like that. ...Some of my staff live alone, some have pets and some don't, so I worry about them the most. We talk about it and then we keep going. Administrator/Supervisor.

Needs of Enrolled Families During COVID-19 When asked how families are doing, staff reported various hardships due to the pandemic, including financial trouble, lack of parenting support, lack of access to mental health services, and transportation and housing challenges.

Financial Assistance The most common need among families was financial assistance due to unemployment; this was mentioned by almost $40 \%$ of staff members ( 23 of 60 ). Home visitors reported that many families have household members who were laid off as a result of the pandemic, causing families to struggle with covering necessities, such as rent and food. Staff also reported that many families are ineligible for unemployment benefits.

Most of our needs are for rental assistance because people were laid off due to the virus and are not able to pay their rent. These are paycheck to paycheck. Sometimes they don't even make it paycheck to paycheck. -Supervisor. 
Parenting Support In the surveys, staff described that families need parenting support, including childcare, internet for their children's schoolwork, and various items, including food (e.g. WIC-eligible food items limited), diapers, and cleaning supplies. Focus groups corroborated that families needed diapers, formula, wipes, or toiletries $(\mathrm{n}=5)$ and food $(\mathrm{n}=4)$.

Most MIECHV families that I have been working with are in need of basic supplies such as diapers, wipes, internet for children's school work. They also need help applying for unemployment as we have tried every method without any luck. -Home Visitor.

Mental Health Services Mental health issues, such as anxiety and depression, were mentioned in the focus groups $(n=4)$. One coordinator reported that, while access to mental health services was already a challenge prior the pandemic, it was now "nearly impossible." Another reported that many mental health providers were not "set up to do telehealth." Intimate partner violence during the pandemic is a severe issue as well, as is reported here by one coordinator.

It was a woman that came on - it wasn't a home visit, but it was a video conference. The home visitor noticed that the woman had essentially marks on her neck. This client was alone, and the home visitor asked just how she's been doing and asked about, 'Oh, what happened?' The woman went on to talk about the abusive relationship that she was in. Some of us might have just frozen in that moment when you see that and not really being sure what to do, but this home visitor, to take the opportunity to make sure she was alone but then to ask her about it. ... A client could have put a scarf around her neck, she could have put make up on to cover the marks, but she didn't. We think that she probably wanted the home visitor to ask her about it. It's such an opportunity for the relationships that the home visitors have with the clients to really be there for them during what is probably a more difficult time right now for women that are living in situations like that." -Supervisor.

Transportation Challenges Staff also mentioned that families experienced transportation and housing challenges challenges due to lack of accessibility for various reasons.

Some are seeing little change because they have no transportation and live in rural areas so they were limited on socializing already. Some have been laid off from low wage jobs with no pay. Some are still working and nervous for their families and what they may be bringing home to them. -Home Visitor.
Our clients continue to worry. They've voiced concerns about the ability to pay rent, lost wages, and the lack of affordable housing which is nothing new to all of us. -Supervisor.

Home Visitor Support to Families Despite the sudden and unexpected transition to virtual home visiting, most home visitors reported continuing their services (communication, support, education, referrals) albeit through different means.

Resources and Supplies Staff reported using time during virtual visits to share resources with families regarding food banks, unemployment benefits, and food stamps.

Most of our needs are for rental assistance because people were laid off due to the virus and are not able to pay their rent. These are paycheck to paycheck. Sometimes they don't even make it paycheck to paycheck. -Administrator/Supervisor.

Our families, like a lot of your families out there, are in service industries that rely solely on tips. -Administrator/Supervisor.

Several coordinators mentioned collaborating with local food banks to provide essential items to families.

The nurses are still going out and dropping off diapers...wipes... whatever the moms may need. I was very skeptical when this whole thing started [virtual home visits] ...but they have been amazing. They picked up the ball, the clients have been so thankful... I'm just so proud of the whole team and all of MIECHV, honestly, because it sounds like everybody's doing the exact same thing... makes me proud to be a part of this. -Administrator/Supervisor.

We connected with [food bank] and my program assistant... made us all masks. We went out and dropped food at people's homes and they were so, so happy about that. They were very relieved. A lot of our foodinsecure families who can't get out were pleased... The first week we had about 41 families. -Administrator/ Supervisor.

Education and Support Moreover, home visitors serve as public health educators by providing information on COVID-19 safety from the CDC and Department of Health and support regarding logistics of their virtual visits based on the families' preferences and technological resources. Additionally, home visitors consider 'checking in' with parents a way to promote self-care.

Making sure that if they can't go outside to walk, they can find a craft or something like that, anything that cooking, whatever it maybe to give them something. I 
don't know. I just ask them about what they're doing to take care of themselves. -Home Visitor.

\section{Resources Needed to Implement Virtual Home Visit-} ing When asked what resources and processes would be most helpful for them right now, tips and activities for conducting virtual visits $(n=8)$, easy access to MIECHV documents $(n=7)$, and self-care activities $(n=7)$. Survey responses reflected the same needs, in addition to assistance for families, including financial assistance for families, and equipment for videoconferencing.

I am having a hard time with reaching some of my families who normally would meet regularly with home visits. A few will not answer the phone or return calls and won't reply back to text messages since this transition. So some suggestions on keeping them engaged through this time of uncertainty would be helpful. -Home Visitor.

\section{Discussion}

Despite the challenges faced by MIECHV staff and administrators during the COVID-19 pandemic, MIECHV staff reported that they were managing effectively and maintaining a sense of confidence and optimism, aided by family engagement and support from MIECHV and other agencies. Participants reported that families are experiencing unique needs due to the pandemic, including financial assistance, parenting support, accessible mental health services, transportation, and housing. MIECHV home visitors have been providing a range of services for families, including resources and supplies, education, and support. Resources requested by MIECHV staff include tips and activities for conducting virtual visits, easy access to MIECHV documents, and self-care activities.

Our findings suggest that the program continues to serve Florida families virtually and to address their needs by providing wraparound, individualized support (Alitz et al. 2018). Virtual platforms allow continuation of communication with the families to assure needed resources, including supplies, health information, mental health services, and referral to other programs, are provided. MIECHV staff and administrators also continue to communicate among themselves to obtain the support and resources needed to successfully serve MIECHV families. Home visitor support is the bedrock of quality services (Alitz et al. 2018), and our results indicate that MIECHV staff feel supported but require additional resources to accommodate virtual home visiting, including videoconference equipment and at-home access to MIECHV documents.
Meanwhile, the nation hopes for an end to the pandemic and braces for the anticipated and unanticipated long-term impacts of COVID-19 on the economy, healthcare system, and society. Vulnerable populations, including pregnant women and children, individuals with low income, and those living in disenfranchised communities will bear the brunt of these impacts. As the respondents in this evaluation noted, it would be helpful to reduce all barriers to providing financial assistance and supplies to help families with their most basic needs before desperation sets in. The federal administration, state agencies, and local programs provide financial relief and benefits; home visitors are an essential connection, and sometimes a lifeline, to those supports for families who may not otherwise have the means or knowledge to access them. Health disparities could continue to exacerbate among this vulnerable population making continuation of support and guidance for these home visiting programs pivotal. As MIECHV programs across the state and nation consider the possibility of continued virtual supports as an augmentation to in-person home visiting or in a hybrid format, findings from this research will guide future efforts to support MIECHV staff and families.

Acknowledgements This work was supported by the Florida Maternal, Infant, and Early Childhood Home Visiting (MIECHV) Initiative, Florida Association of Healthy Start Coalitions, Inc. Project \#6405107050 (Funded by the Health Resources and Services Administration (HRSA) of the U.S. Department of Health and Human Services (HHS), Grant \#FY18, X10MC29478).

\section{References}

Alitz, P., Geary, S., Birriel, P. C., Sayi, T., Ramakrishnan, R., Balogun, O., et al. (2018). Work-related stressors among MIECHV home visitors: A qualitative study. Maternal \& Child Health Journal, 22(Supplement 1), 62-39. https://doi.org/10.1007/s1099 5-018-2536-8.

Centers for Disease Control and Prevention. (2020a). Cases in U.S. Retrieved from https://www.cdc.gov/coronavirus/2019-ncov/cases -updates/cases-in-us.html\#cumulative

Centers for Disease Control and Prevention. (2020b). Situation Summary. Retrieved from https://www.cdc.gov/coronaviru s/2019-ncov/casesupdates/summary.html?CDC_AA_refVa $1=$ https $\% 3 \mathrm{~A} \% 2 \mathrm{~F} \% 2 \mathrm{Fwww} . \mathrm{cdc}$.gov $\% 2 \mathrm{Fcoronavirus} \% 2 \mathrm{~F}$ 2019-ncov\%2Fsummary.html\#emergence.

Cluver, L., Lachman, J. M., Sherr, L., Wessels, I., Krug, E., Rakotomalala, S., et al. (2020). Parenting in a time of COVID-19. Lancet (London, England), 395(10231), e64. https://doi.org/10.1016/ S0140-6736(20)30736-4.

Dashraath, P., Wong, J. L. J., Lim, M. X. K., Lim, L. M., Li, S., Biswas, A., et al. (2020). Coronavirus disease 2019 (COVID-19) pandemic and pregnancy. American Journal of Obstetrics and Gynecology. https://doi.org/10.1016/j.ajog.2020.03.021.

Du Toit, A. (2020). Outbreak of a novel coronavirus. Nature Reviews. Microbiology, 18(3), 123. https://doi.org/10.1038/s4157 9-020-0332-0.

Dunn, C. G., Kenney, E., Fleischhacker, S. E., \& Bleich, S. N. (2020). Feeding low-income children during the Covid-19 pandemic. 
The New England Journal of Medicine, 382(18), e40. https://doi. org/10.1056/NEJMp2005638.

Florida Department of Health. (2020). Florida's COVID-19 Data and Map Dashboard. Retrieved June 22, 2020 from: https://experience .arcgis.com/experience/96dd742462124fa0b38ddedb9b25e429.

Florida MIECHV (FLMIECHV). (2019). Demographics and Services Utilization Report. Retrieved April 14, 2020 from https://www. flmiechv.com/wpfl-content/uploads/FL-MIECHV-Demographi cs-Service-Utilization-Report-2019.pdf

Holshue, M. L., DeBolt, C., Lindquist, S., Lofy, K. H., Wiesman, J., Bruce, H., et al. (2020). First case of 2019 novel coronavirus in the United States. The New England Journal of Medicine, 382(10), 929-936. https://doi.org/10.1056/NEJMoa2001191.

Marshall, J., Birriel, P. C., Baker, E., Olson, L., Agu, N., \& Estefan, L. (2018). Widening the scope of social support: The Florida Maternal, Infant, and Early Childhood Home Visiting program. Infant Mental Health Journal, 39(5), 595-607.

Qiao, J. (2020). What are the risks of COVID-19 infection in pregnant women? Lancet (London, England), 395(10226), 760-762. https ://doi.org/10.1016/S0140-6736(20)30365-2.
U.S. Department of Health and Human Services. (2020a). Determination that a Public Health Emergency Exists. Retrieved from: https://www.phe.gov/emergency/news/healthactions/phe/Pages /2019-nCoV.aspx

U.S. Department of Health and Human Services. (2020b). HHS awards $\$ 15$ million to support telehealth providers during the COVID19 pandemic. Retrieved from: https://www.hhs.gov/about/ news/2020/05/13/hhs-awards-15-million-to-support-telehealth -providers-during-covid19-pandemic.html

Zero to Three. (2020). States modify home visiting services in response to COVID-19. Retrieved from: https://www.zerotothree.org/resou rces/3315-states-modify-home-visiting-services-in-response-tocovid-19

Publisher's Note Springer Nature remains neutral with regard to jurisdictional claims in published maps and institutional affiliations. 